\title{
PRÁTICAS DE ENSINO A PARTIR DA INCLUSÃO DO TEMA TRANSVERSAL PLURARIDADE CULTURAL: ANÁLISE DE PROJETOSNA ESCOLA ESTADUAL DR. FERNANDO ABBOTT - SÃO GABRIEL/RS.
}

\author{
Angela Alessio Longhi ${ }^{1}$; Jefferson Marçal da Rocha ${ }^{2}$ \\ ${ }^{1}$ Professora da Escola Municipal de Ensino Fundamental Dom Pedro II e Pós-graduada em Interdisciplinaridade e \\ Transversalidade, Universidade Federal do Pampa, Campus São Gabriel. \\ anglonghi@hotmail.com \\ ${ }^{1}$ Professor Adjunto da Universidade Federal do Pampa. \\ jeffersonmrocha@gmail.com
}

\section{RESUMO}

Este artigo refere-se ao estudo de projetos extracurriculares desenvolvidos na Escola Estadual Dr. Fernando Abbott, do município de São Gabriel-RS, que tiveram a intenção de incorporar os temas transversais, em especial, a Pluralidade Cultural em seu currículo. Foram avaliados os projetos disponíveis na supervisão escolar, realizadas entrevistas com professores e direção da Escola, onde se constatou que a maioria dos projetos propostos contemplou os Temas Transversais, sendo que a Pluralidade Cultural esteve evidenciada mais especificamente na realização do "Projeto Consciência Negra". Estepropiciou de maneira interdisciplinar, um resgate histórico eculturalque valorizou as diversidades étnicas. Nesta investigação,percebeu-se o quanto a abordagem deste tema oferece um campo extremamente diversificado e importante, que deve ser inserido no processo ensino-aprendizagem de forma contextualizada e permanente.

Palavras-chave: Projetos de Ensino, Temas Transversais, Pluralidade Cultural.

\section{ABSTRACT}

This article studies extracurricular projects developed at a Brazilian Public School name Escola Estadual Dr Fernando Abbott located in São Gabriel, Rio Grande do Sul State, which had the intention to incorporate the Transversal Subjects, in special, the Cultural Plurality in its Educational Program. The available projects were evaluated as well as the interviews done with teachers and the members of the Principal Office. After doing that we got to the conclusion that almost all the projects have taken into consideration those Transversal Subjects and that Cultural Plurality was accomplished during the realization of the Project called "ConsciênciaNegra" (or Black Consciousness) about African contribution to Brazilian Culture, including not only Art, History, Food, Religious aspects but also the situation of afro Brazilians into contemporary society. This paper has demonstrated how rich and meaningful this subject can be if we use it permanently.

Keywords: Educational Projects, Cross-cutting Themes, Cultural Plurality. 


\section{INTRODUÇÃO}

A sociedade é uma construção humana. Esta afirmação nos remete a pensarmos sobre a importância que a educação tem em nossas vidas e sua dimensão em termos de aprimoramento e gerenciamento sequenciais do desenvolvimento humano. Uma sociedade mais justa e humana, só será possível, a partir da conscientização de que todos devem ter as mesmas oportunidades quanto ao processo ensino-aprendizagem e quanto à qualidade deste processo (FREIRE, 2000).

Neste contexto, parte-se da concepção que é necessário motivar mudanças na Educação. No cenário educacional brasileiro, se evidencia no Plano de Desenvolvimento da Educação (PDE), a procura para superar defasagens históricas ao se propor que a educação seja tratada como unidade, ampliando o horizonte educacional de todo independente, de etnia, credo ou classe social.

Porém apesar desta perspectiva nota-se que a pedagogia usada pela grande parte dos educadores, pouco evoluiu dos séculos atrás. Ao invés de agregarem os seus conhecimentos com informações externas, prendem seus planos de aula em conteúdos específicos de um ou dois autores, esquecendo todo o universo de informações (FREIRE, 2000).

Seria essencial que os educadores incentivassem seus alunos a buscar informações as quais eles julgassem necessárias, para serem discutidas em aula. Fazendo com que a busca pessoal das informações, que julgam importantes, se agregassem no valor do conhecimento, auxiliando-os no aprendizado. O educador, além de passar conteúdos pragmáticos técnicos, deveria orientar conceitos, estimular discussões e interações, contextualizando saberes de suas vidas nas práticas diárias vivenciadas na escola (FREIRE, 2000).

A sociedade contemporânea esta marcada por avanços tecnológicos que mudaram significativamente a vida em sociedade. Através de novos meios de comunicação aparentemente, houve uma democratização do conhecimento.

Neste contexto a educação deve caminhar para formar todos indistintamente. Pessoas que se comuniquem, trabalhem em equipe, que se adaptem facilmente a novas situações, que estejam em permanente formação e principalmente, que sejam autônomas. Isso implica que o profissional da educação precisa, ter um olhar desafiador e práticas inovadoras. Esta nova concepção de educador atual precisa ter o perfil de trabalho que explore os conhecimentos prévios, saberes e competências de cada educando e trabalhe com os meios tecnológicos como suporte de motivação. O professor precisa mudar suas práticas constantemente, para possibilitar que seus alunos sejam questionadores, que cresçam e queiram fazer parte dessa mudança. Para isso, ressalta-se a importância de uma política pública que valorize e dê suporte para este profissional.

Nessa perspectiva de mudanças, questionamo-nos constantemente quanto à importância da organização curricular, ligada primordialmente a planejamento educacional. Devemos nos conscientizar que planejamento é o grande aliado dos educadores frente à organização e garantia de qualidade da prática docente diária. O educador deve estabelecer como prioridade do seu 
trabalho o ato de diagnosticar, planejar, executar, avaliar e ter o cuidado de replanejar sempre que houver necessidade. A fim de estabelecer mecanismos que o assegure que sua prática está tendo êxito (FREIRE, 2000).

A mesma importância se dá quanto à elaboração do plano de aula interdisciplinar e flexível. A metodologia escolhida para esta práxis também é fator determinante para que haja satisfatoriamente a aprendizagem, pois a mesma deve ser nutrida e regada pela reflexão constante da ação.

O ensino por projetos, elaborados em conjunto com a comunidade escolar, certamente poderá ser uma importante ferramenta para se alcançar os objetivos de uma educação transformadora.

O uso dos temas transversais no cotidiano escolar como instrumento auxiliador do desenvolvimento de habilidades é importante tanto para o educador como para o educando. Assim como aabordagem de temas como a pluralidade cultural que procuram estimular a reflexão sobre a formação étnica da sociedade brasileira e suas múltiplas culturas. A partir da compreensão do pluralismo de identidades, procura-se valorizar as diferentes heranças culturais da população brasileira (PCN, p.15).

\section{EDUCAÇÃO E CIDADANIA: DESAFIOS DO EDUCADOR DO SÉCULO XXI}

A educação para a cidadania tem sido uma das principais preocupações dos pedagogos e dos sistemas educacionais de todo mundo. A sociedade do século XXI apresenta desafios e paradoxos que a educação passou a enfrentar.

Há necessidade de nos relacionarmos num contexto que é cada vez mais multicultural e heterogéneo, ao mesmo tempo em que se verifica uma pressão para a homogeneidade e o aumento das incertezas sobre a própria identidade individual e coletiva.

Entretanto, uma análise mostra que sutilmente os direitos de cidadania estão dissolvidos em uma reconfiguração do termo, apontando para um novo tipo de cidadão no século XXI. Um exemplo disso é que a inserção na sociedade pós-moderna atualmente se dá através da capacidade de consumo de bens materiais, ou seja, está relacionada não mais à participação social e ao uso dos direitos e deveres, mas à posição econômica que permite ou não o acesso ao consumo (ROCHA, 2011).

A prática da cidadania encontra-se desvinculada das esferas políticas e institucionais, está idealizada através do acesso aos bens de consumo. Fato que inviabiliza o papel do ensino como forma de conscientização na sociedade, uma vez que o mesmo não é visto como um bem de consumo em potencial. Assim, mais que em épocas passadas "A escola deve abrir o horizonte intelectual do estudante, colocando conteúdos que tornem a educação um instrumento não só para a vida, mas para a transformação da vida e da sociedade" (FERNANDES, 1989, p.68). 
Esse pensamento torna clara a função educacional voltada para o cidadão, ou seja, o "horizonte intelectual" dos indivíduos pode ou não possibilitar as mudanças, favorecendo ou não para o progresso do país nos seus aspectos político, cultural e econômico.

Jacques Delors (1998) aponta como principal consequência da sociedade do conhecimento a necessidade de uma aprendizagem ao longo de toda vida, fundamentada em quatro pilares, que são, concomitantemente, pilares do conhecimento e da formação continuada.

A seguir, uma síntese dos quatro pilares para a educação do século XXI:

Aprender a conhecer: É necessário tornar prazeroso o ato de compreender, descobrir, construir e reconstruir o conhecimento para que não seja efêmero, que se mantenha através do tempo, que valorize a curiosidade, a autonomia e a atenção, permanentemente. É preciso também pensar o novo, reconstruir o velho, reinventar o pensar.

Aprender a fazer: Não basta preparar-se com cuidados para inserir-se no setor do trabalho. A rápida evolução por que passam as profissões pede que o indivíduo esteja apto a enfrentar novas situações de emprego e a trabalhar em equipe, desenvolvendo espírito cooperativo, de humildade na reelaboração conceitual e nas trocas, valores necessários ao trabalho coletivo. Ter iniciativa, gostar de certa dose de risco, ter intuição, saber comunicar-se, saber resolver conflitos e ser flexível. Aprender a fazer envolve uma série de técnicas a serem trabalhadas.

Aprender a viver junto: No mundo atual este é um importantíssimo aprendizado, por ser valorizado quem aprende a viver com os outros, a compreender os outros, a desenvolver a percepção de interdependência, a administrar conflitos, a participar de projetos comuns, a ter prazer no esforço comum.

Aprender a ser: É importante desenvolver sensibilidade, sentido ético e estético, responsabilidade pessoal, pensamento autônomo e crítico, imaginação, criatividade, iniciativa e desenvolvimento integral da pessoa em relação à inteligência. A aprendizagem precisa ser integral, não negligenciando nenhuma das potencialidades de cada indivíduo.

Uma educação fundamentada nos quatro pilares acima elencados sugere procedimentos didáticos que Ihe sejam condizentes, como: Relacionamento do tema com a experiência do estudante e de outros personagens do contexto social; Desenvolvimento da pedagogia da pergunta (FREIRE, 1985); Relação dialógica com o estudante; Envolvimento do estudante num processo que conduz a resultados, conclusões ou compromissos com a prática; Processo de autoaprendizagem, corresponsabilidade no processo de aprendizagem; Utilização do jogo pedagógico com o princípio de construir o texto.

\section{OS PARÂMETROS CURRICULARES NACIONAIS E OS TEMAS TRANSVERSAIS}

O debate sobre a questão da cidadania é hoje diretamente relacionado com a discussão sobre o significado e o conteúdo da democracia, sobre as perspectivas e possibilidades de construção de uma sociedade democrática. Nessa concepção a noção de cidadania tem um significado preciso: abrange exclusivamente os direitos civis (liberdade de ir e vir, de pensamento e expressão, direito à integridade física, liberdade de associação) e os direitos políticos (eleger e ser eleito), sendo que seu exercício se expressa no ato de votar. Porém numa concepção mais abrangente, a noção de cidadania ganha novas dimensões.A conquista de significativos direitos 
sociais nas relações de trabalho, previdência social, saúde, educação e moradia, amplia-se a concepção restrita de cidadania cível e política.

Os movimentos sociais revelam as tensões que expressam a desigualdade social e a luta pela crescente equidade na participação ou ampliação dos direitos. Assim como da relação entre os direitos individuais e os coletivos e da relação entre os direitos civis, políticos, sociais e econômicos como os Direitos Humanos.

Na medida em que boa parte da população brasileira não tem acesso a condições de vida digna, encontra-se excluída da plena participação nas decisões que determinam os rumos da vida social (suas regras, seus benefícios e suas prioridades). É nesse sentido que se fala de ausência de cidadania, cidadania excludente ou regulada, caracterizando a discussão sobre a cidadania no Brasil (PARÂMETROS CURRICULARES, 2001).

Novos autores, direitos, mediações e novas instituições redefinem o espaço das práticas cidadãs, propondo o desafio da superação da marcante desigualdade social e econômica da sociedade brasileira, tendo como consequência a exclusão de grande parte da população na participação dos direitos e deveres. Trata-se de uma noção de cidadania ativa, que tem como ponto de partida a compreensão do cidadão como portador de direitos e deveres, além de considerá-lo criador de direitos, condição que lhe possibilita participar da gestão pública (PARÂMETROS CURRICULARES, 2001).

No âmbito educativo, são fundamentos que permitem orientar, analisar, julgar, criticar as ações pessoais, coletivas e políticas na direção da democracia. Os Parâmetros Curriculares Nacionais, ao proporem uma educação comprometida com a cidadania, foram baseados no texto constitucional, princípios que orientam a educação escolar: Dignidade da pessoa humana - Implica em respeito aos direitos humanos, acesso a condições de vida digna, respeito mútuo nas relações interpessoais públicas e privadas; Igualdade de direitos - Refere-se à necessidade de garantir a todos a mesma dignidade e possibilidade de exercício de cidadania; Corresponsabilidade pela vida social - Implica em partilhar com os poderes públicos e diferentes grupos sociais, organizados ou não, a responsabilidade pelos destinos da vida coletiva.

Neste contexto, os parâmetros curriculares nacionais foram elaborados na década de 1990 procurando de um lado, respeitar diversidades regionais, culturais, políticas existentes no país e, de outro, considerar a necessidade de construir referências nacionais comuns ao processo educativo em todas as regiões brasileiras. Com isso, pretendeu-se criar condições, nas escolas, que permitissem aos nossos jovens ter acesso ao conjunto de conhecimentos socialmente elaborados e reconhecidos como necessários ao exercício da cidadania.

O conjunto de temas proposto nos PCNs - Ética, Meio Ambiente, Pluralidade Cultural, Saúde, Orientação Sexual, Trabalho e Consumo - recebeu o título geral de Temas Transversais, indicando a metodologia proposta para sua inclusão nos currículos escolares e seu tratamento didático. Abrange tanto a crítica das relações entre os grupos, dos grupos nas instituições e ante elas, quanto à dimensão das ações pessoais. Trata-se, portanto de discutir o sentido ético da convivência humana nas suas relações com várias dimensões da vida social: o ambiente, a cultura, o trabalho, o consumo, a sexualidade e a saúde.

Com a compreensão e a valorização da comunidade escolar sobre os temas transversais, a educação para cidadania passou a estar explícita nas práticas educacionais. Neste contexto, o ambiente escolar deve propiciar, através do entendimento de vários segmentos importantes relacionados aos temas transversais, a valorizaçãoda complexidade social. 
O convívio escolar refere-se a todas as relações e situações vividas na escola, dentro e fora da sala de aula, em que estão envolvidos direta ou indiretamente todos os sujeitos da comunidade escolar. O trabalho com os temas sociais se concretizará nas diversas decisões tomadas pela comunidade escolar, o que aponta a necessidade de envolvimento de todos no processo de definição do trabalho e das prioridades a serem eleitas. Cada um - alunos, professores, funcionários e pais - terá função neste processo. Para isso, é importante que as instâncias responsáveis pelas escolas criem condições, que a direção da escola facilite o trabalho em equipe dos professores e promova situações favoráveis à comunicação, ao debate e à reflexão entre os membros da comunidade escolar.

Para os chamados professores polivalentes ${ }^{3}$ de primeiro e segundo ciclos, essas situações serão especialmente valiosas para que possam definir a forma de trabalhar com os Temas Transversais a partir da realidade de cada um e dentro das possibilidades da escola.

O desenvolvimento dos temas transversais no contexto escolar é uma atitude que deverá envolver toda a comunidade escolar, onde todos devem falar a mesma linguagem e trabalhar em rede para a eficácia dos objetivos propostos.

O educador deve estar baseado em planos e projetos coerentes e significativos, objetivando motivar e envolver os alunos nessas dinâmicas. A escolha do tema transversal a ser desenvolvido deve seguir a intuição do bom educador em perceber através dos comentários e debates entre os alunos, a melhor oportunidade de abordar um tema a fim de esclarecer e ampliar tais conhecimentos, de maneira lúdica e espontânea. A escola, juntamente com a equipe, diretiva deve subsidiar estas práticas, apoiando de maneira que venha a contribuir no processo ensinoaprendizagem como um todo. A mesma deve possibilitar trabalhos e projetos conjuntos, envolvendo a comunidade escolar a participar e ingressar nesta perspectiva interdisciplinar e temática.

Os conteúdos tradicionais continuam sendo os referenciais do sistema educacional. 0 objetivo da escola continua sendo trabalhar os conteúdos tradicionais (Matemática, História, Química, Física, Biologia, Línguas, etc.) transversalmente, perpassando estes conteúdos, os temas mais vinculados ao cotidiano, que são: ética, meio ambiente, orientação sexual, pluralidade cultural, trabalho e consumo e saúde.

Com isso, os temas transversais passaram a ser mais uma forma de incluir as questões sociais no currículo escolar, que se enriquece através da flexibilidade, uma vez que os temas podem ser contextualizados e trabalhados de acordo com as diferenças locais e regionais.

\section{PRÁTICAS PEDAGÓGICAS QUE CONTEMPLEM OS TEMAS TRANSVERSAIS}

Os Parâmetros Curriculares Nacionais constituem um referencial de qualidade para educação em todo o País. Sua função é orientar e garantir coerência dos investimentos do sistema educacional, socializando discussões, pesquisas e recomendações, subsidiando a participação de técnicos e professores brasileiros.

\footnotetext{
${ }^{3}$ Que pode ter vários usos: uma sala polivalente; que exerce diversas funções: um empregado polivalente; que diz respeito a vários domínios: um instituto polivalente. 
A prática de todo professor deve pressupor uma concepção de ensino e aprendizagem que determine sua compreensão dos papéis de professor e aluno, da metodologia, da função social da escola e dos conteúdos a serem trabalhados.

A discussão dessas questões é importante para que se explicitem os pressupostos pedagógicos que subjazem à atividade de ensino, na busca de coerência entre o que se pensa estar fazendo e o que realmente se faz. Tais práticas se constituem a partir das concepções educativas e metodologias de ensino que permearam a formação educacional e o percurso profissional do professor, aí incluídas suas próprias experiências escolares, suas experiências de vida, a ideologia compartilhada com seu grupo social e as tendências pedagógicas que lhe são contemporâneas.

Segundo Martins (1995), o ensino é sempre mais do que ensinar. O ato pedagógico não vale por si mesmo, vale pelo que é capaz de engendrar para a sociedade e o grupo social do qual ele derivou e para o qual ele deve se voltar para produzir a realidade social. Nesta perspectiva, o cotidiano escolar é compreendido como campo investigativo no qual se inscreve a prática pedagógica e como tempo vivido nas trocas subjuntivas, assumindo lugar de destaque nos processos de apropriação significativa de conhecimentos. É na produção da realidade social, pelos meios pedagógicos, que o professor é um agente político; ele põe em evidência as relações sociais, pois transmite modelos sociais, seja de autoridade, de respeito, de polidez, de oposição à estrutura social mais complexa (MARTINS, 1995). Como agente político, o professor tem importante responsabilidade com a formação dos seus alunos.

De acordo com Sartori e Weschenfelder (2007, p. 49),

Para Paulo Freire, o rigor do saber no campo social não decorre de um exercício individual e solitário do intelectual fechado entre quatro paredes ou num laboratório, mas pelo exercício coletivo de construção de saberes necessários para a instauração de uma situação de vida mais qualificada e decente. O rigor científico não surge somente da intimidade silenciosa com os livros, mas pode decorrer da relação reflexiva e crítica com os outros. Afinal, todo o conhecimento sempre tem uma origem social e a ele se destina. (FREIRE,1996, p.17)

Daí a necessidade de tomadas coletivas de decisões sobre o ensino, que nos levam a compreender o planejamento em sua dimensão colegiada, ou seja, coletiva. Os professores devem aprender uns com os outros como melhor ensinar, divulgando êxitos e dificuldades, buscando aprofundamento teórico e, sobretudo, responsabilizando-se como grupo por suas opções. Deve-se incluir nesse percurso formador o risco de cometermos enganos e, consequentemente, a vigilância para que sejam capazes de refazer ou retomar percursos falseados.

Duvidar de certezas é um exercício de aprendizagem constante para a docência, podendo cair-se em práticas pedagógicas voltadas a silenciar as diferenças culturais. Nossa opção pelo desocultamento das desigualdades sociais faz com que suspeitemos do consenso, pois este pode camuflar interesses individualizados e, assim, perpetuar desigualdades. Através da prática pedagógica, o professor inculca ideal de liberdade, de honestidade, de justiça, de solidariedade e assim coloca em evidência o conflito social, seja pela sugestão do modelo opressor ao qual o aluno deve sujeitar-se, seja por deixar evidentes as relações de força entre os grupos sociais, inclusive entre ideais opostos. 
É preciso considerar as oportunidades de mudanças advindas do debate, pois os conflitos vividos cotidianamente são partes do projeto político-pedagógico em curso na escola, na busca por consensos sempre provisórios ou, nas palavras de Apple (1989), na busca por "coalizações sociais".

Quando se fortalece as escolhas no coletivo, sem abrir mão da criticidade necessária para que se evite a pasteurização dos discursos e das práticas, aumentam as chances de sucesso. Desse modo, os momentos individuais do planejamento estarão respaldados no diálogo com o colegiado do qual somos parte, bem como na teoria que fundamenta nossas concepções e práticas.

Para Paulo Freire (2003), a questão da transformação da prática pedagógica em prática dialógica defende a ideia de que a ação pedagógica deve ser uma ação dialógica; o diálogo num contexto de aprendizagem não inicia com uma fala sobre um assunto qualquer dos alunos. A ação pedagógica envolve, desde o início, uma condução teórico-metodológica de parte do educador, o que não significa dizer que o professor, nos moldes da educação autoritária, tenha um saber a impor ou uma verdade a revelar aos alunos.

A prática pedagógica é a oportunidade para que se dê a passagem do objetivo, isto é, do dado real, concreto, histórico, ao subjetivo. Por outro lado, o subjetivo, o aluno e sua história, aparecem como necessário à superação em direção ao objetivo. Ora, para que as relações materiais que governam as relações humanas se tornem práxis, necessitam de um sujeito particular, na singularidade das situações vividas por ele. Essas situações são a motivação para que o aluno possa redimensionar sua atuação e lançar-se em nova objetividade, vale dizer, o vivido aparece já modificado no resultado final da ação.

Considera-se como etapa inicial do ciclo do planejamento docente o estudo da prática pedagógica na escola. Com isso, afirma-se a ligação entre planejamento e a reflexão sobre a prática do ensino e, assim, insere-se a atividade de pesquisa no cotidiano escolar. Por não ser apenas um meio para executar programas oficiais, o ato de planejar é aqui entendido como parte constituinte do processo de produção do saber didático na escola.

O professor é o elemento intelectual capaz de realizar materialmente o nexo teoria-prática, desenvolvendo sua atividade educativa como um ser histórico social.

O recurso original que o educador tem nas mãos é o aluno, um ser em formação/transformação. A educação negaria a si mesma se supusesse o homem como um ser acabado, pois a educação é um tanto enriquecida pelo fato do sujeito estar aí como resultado das suas próprias transformações decorrentes da possibilidade humana de criar a realidade.

Essa possibilidade é mais forte no âmbito da prática docente porque o professor vai atuar sobre a personalidade, a consciência do aluno com conteúdos, ideias e valores. Através dessa especificidade é que a práxis pedagógica participa da criação da realidade. Assim, anuncia-se claramente a aproximação entre ensino e pesquisa, entre pesquisa e ação pedagógica.

Quando se diz que o estudo da prática pedagógica na escola inaugura o ciclo do planejamento docente, refere-se a um conjunto de definições conceituais, a saber, o contexto escolar e os sujeitos pesquisados. Há dois momentos nessa prática consciente: um de análise, superação da alienação e outro de proposta de ação.

A prática concreta pode oferecer os elementos para análise. É nela que o professor pode perceber objetivamente as contradições entre o que ele pratica e o resultado dessa prática. É através dela que se educa e orienta os educandos em suas decisões. Orienta no contínuo redimensionamento de sua práxis, de tal modo que, por esta sintonia entre o que ele faz e o que 
pensa, forme-se uma cadeia na qual se dispõem progressivamente os passos, e na qual não se rompa o vínculo entre a teoria e a prática, entre os meios e os fins, entre consciência e ação.

Primeiramente, especifica-se o contexto escolar como decisivo para que este estudo seja possível. Em outras palavras, o cotidiano escolar é o campo da atividade investigativa pretendida e é a partir das práticas culturais nele desenvolvidas que os temas a serem estudados vêm à tona. Essa observação é fundamental porque revela a escola como espaço formador, como lugar de produção de conhecimento, a qual funciona como lugar de encontro entre sujeitos e suas visões de mundo e nela os assuntos levantados para estudo guardam especificidades relacionadas às necessidades da prática educativa.

Seria muito artificial levantar situações-problema para aprofundamento didático desconsiderando o contexto escolar, as pessoas e os desafios do cotidiano. Também seria muito raso banalizar as situações cotidianas, reduzindo as problemáticas educacionais ao senso comum. Portanto, olhar com estranheza o cotidiano implica teorizá-lo, conectando-o com a trama social maior, pois o "enfoque nas questões miúdas do cotidiano escolar não faz perder a dimensão política e menos social" (MCLAREN, 2000).

Pensa-se a escola como o espaço real no qual os professores constroem sua identidade profissional.Logo, é um espaço formador não apenas para os educandos, mas também para os docentes. Assim, caracteriza-se a escola como espaço dialógico e de cruzamentos identitários, um espaço plural, que reúne conflitos, valores partilhados ou contestados. Nela, os sujeitos estabelecem redes coletivas de trabalho (NÓVOA, 1999), decisivas para o profissionalismo das práticas de ensino e também nas aprendizagens construídas pelos educandos.

Essa primeira definição elimina logo de início a ideia de que o ato de planejar é individual. Quando contextualizamos nosso ensino na trama social maior e quando nos vemos em interação nos ambientes de troca dos quais participamos, percebemos que é impossível abstrair o nosso fazer, como se nada tivéssemos a ver com as opções político-pedagógicas desenhadas em nossos contextos de inserção profissional. Portanto, o estudo da prática pedagógica não é solitário, tampouco o ensino é alheio às tomadas de posições dos sujeitos diante dos desafios cotidianos. Constantemente, o professor precisa recorrer aos outros para partilhar as motivações e as escolhas que fundamentam sua docência (ARAUJO, 2000).

Cotidianamente, a organização escolar vai revelando os sujeitos em seus posicionamentos, interações, partilhas, histórias de vida, pontos de vista, modos de agir e pensar, expectativas, sentimentos, enfim, nas suas identidades pessoais e culturais. Diariamente, os professores se veem impelidos a responder aos problemas vividos nos seus espaços de atuação, seja pensando sobre sua própria inserção na escola como um todo, seja mais especificamente, pensando sobre o trabalho na sala de aula. E, quando a organização escolar consegue criar condições propícias ao estudo da prática pedagógica, os profissionais da educação passam a elaborar melhor os saberes didáticos, lendo o cotidiano em suas minúcias. Assim, a escola torna-se ainda mais poderosa na sua tarefa formadora, pois favorece a criação por parte do coletivo docente de variadas situações de estudo sobre a própria inserção profissional.

Desse modo, os educadores tornam-se investigadores do próprio cotidiano; e ainda mais capazes de sistematizar a própria experiência, afirmando suas identidades profissionaisna relação com o desenvolvimento do ensino. A escola vai se construindo como uma organização aprendente (HARGREAVES; FULLAN, 2000), pois qualifica o ensino à medida que seus professores se desenvolvem. 
Quando se problematiza o cotidiano escolar, faz-se isso com base nas necessidades da docência, ou seja, colocam-se em pauta as dificuldades, as estratégias de ensino, as dúvidas e as conquistas dos educandos. Assim, relaciona-se os objetos de investigação com os desafios do ensino-aprendizagem.

Paulo Freire (1997, p. 32), ilustra essa questão com a seguinte afirmação: "Ensino porque busco, porque indaguei, porque indago e me indago. Pesquiso para constatar, constatando intervenho, intervindo educo e me educo. Pesquiso para conhecer o que ainda não conheço e comunicar ou anunciar a novidade".

A prática pedagógica, como ferramenta simbólica possibilita a promoção de situações de ensino-aprendizagem, pois necessita vincular tanto a vida cotidiana quanto as crises que pulsam na escola e nos espaços não escolares. É preciso considerar que a relação pedagógica é uma relação essencialmente humana; portanto, até que ponto as relações pedagógicas no cotidiano da escola produzem mais "humanidade". A complexidade das relações humanas, cujos reflexos se estendem à prática pedagógica, necessita de considerações aos significados culturais que produz e reproduz no espaço escolar e social.

De acordo com Sartori e Weschenfelder (2007, p. 14),

[...] a prática pedagógica se constitui numa prática política intencionada, a qual traz no seu bojo questões de natureza ética e metodológica, haja vista que a intencionalidade necessita de definições sobre o sentido da vida humana na sociedade. Desse modo, a prática necessita ser refletida não de forma mecânica, isolada, inconsciente, mas com base numa compreensão antropológica que auxilie na análise das situações em que o discurso diverge da prática docente. Por isso, antes de pensar a mudança, precisamos construir compreensões sócias antropológicas.

Dessa forma, considera-se o pensar a prática como um exercício formador dos sujeitos, ou seja, o estudo da prática pedagógica na escola é configurado como um trabalho investigativo complexo que reúne uma riqueza de situações desafiadoras, diante das quais o ensino se efetiva. Ao serem analisadas na coletividade do espaço escolar, tais práticas pedagógicas passam a ser problematizadas e interpretadas segundo um trabalho de pesquisa dialético que mobiliza a ação dos sujeitos conforme o duplo objetivo de transformar a realidade e produzir conhecimentos relativos a essa transformação (CANDAU; LEITE, 2007).

Encarar a prática docente deste modo traz consequências. Implica a formulação de um novo projeto cultural e por ele um novo currículo. Implica uma nova escola onde as relações naturais que nela se realizam serão resultantes da relação educador-educando-meio. Discute-se, então, a produção coletiva do saber didático na escola, considerando o ensino-aprendizagem como trabalho intelectual voltado à transformação social.

Para viver democraticamente em uma sociedade plural é preciso respeitar os diferentes grupos e culturas que a constituem. Nesse sentindo, a escola deve ser local de diálogo, de aprender a conviver, vivenciando a própria cultura e respeitando as diferentes formas de expressão cultural.

No Brasil, onde as raças se misturam, onde existem raízes de diversas culturas, é indispensável uma proposta de ensino direcionado à Pluralidade Cultural, contextualizando conteúdos, com o objetivo de formar e informar os agentes que fazem parte do processo de ensino-aprendizagem, educadores e educandos, para que os mesmos construam conceitos e 
adquiram conhecimentos importantes para uma convivência harmônica na atual sociedade em que vivemos (PCNs, 2001).

A Pluralidade Cultural oferece, dentro do trabalho pedagógico, uma forma dos educandos conhecerem suas origens, sua história como um cidadão participante de um determinado grupo social. Ainda podemos colocar a questão de um trabalho onde o próprio educador faz o papel do mediador na aquisição de conhecimentos.

Dentro deste contexto, a escola entra como um local de aprendizagem que permite a compreensão do significado do trabalho sobre Pluralidade Cultural, pois isto se dá a cada momento em que convivemos com diferentes etnias no âmbito educacional. O aprendizado não ocorre com discursos já pré-determinados, mas sim, a partir do cotidiano onde o discurso seja de que todos são iguais, independente de nossa raça. Este trabalho deve almejar o compromisso ético para a contribuição necessária de uma sociedade baseada em valores mais justos e democráticos.

Supostamentevivemos em uma sociedade que se diz democráticas. Mas onde mesmo que acontece esta democracia? Será que ela realmente existe dentro de um contexto no qual a pobreza toma conta de nossas periferias? A marginalização da sociedade em grupos sociais de baixa renda deixa claro que a democracia acontece apenas em determinados setores da sociedade vigente.

Esta sociedade que se almeja está baseada em princípios éticos como a igualdade entre os seres, o respeito mútuo, justiça e equidade, sendo que estes mesmos valores estão impressos em nossa Constituição Federal. Diante deste segmento, devemos dar ênfase ao trabalho da pluralidade, pois deve ser um trabalho construído através de um envolvimento de todos na conquista do respeito a esta diversidade cultural incontestável dentro da nossa sociedade.

Este tema em questão torna-se um tema atual e urgente a partir do momento em que a própria escola se propõe a desenvolver um trabalho direcionado à diversidade cultural de nosso país. Neste sentido, respeitar e valorizar estas diversidades devem estar dentro da fundamentação do currículo de nossas escolas, no qual se reconhece essas diferenças para que privilegiem o nosso aluno, tornando evidente e necessária a construção de experiências educativas que ensinemao nosso aluno diferentes maneiras de existir socialmente e de criar suas próprias expectativas para o seu futuro, tornando-o mais autônomo e solidário.

O processo de construção destes valores se dá a partir de um trabalho educacional cujos princípios estejam ligados a uma concepção de educação que visa o desenvolvimento integral do Ser Humano, no qual as relações entre os sujeitos provoquem a transformação baseada na ligação do saber específico com o conhecimento cultural de sua origem.

O Brasil é constituído por uma sociedade múltipla, várias etnias o constituem, como índios, africanos, europeus, latinos e, de acordo com esta diversidade é que os PCN's propõem que a formação do educando deve estar direcionada a construção de suas habilidades e competências, bem como conhecer e conviver com a diversidade, pois assim a crianças aprende a respeitá-la.

Devem-se apresentar propostas direcionadas à aquisição de conhecimentos que incorporem características que favoreçam o aprendizado de elementos de várias culturas, para que realmente ocorra a transformação do pensar e o agir em relação à multiplicidade de nossa nação.

A escola deve apresentarcomo principal protagonista dessa construção, pois é através dela que o ser social em desenvolvimento passa a entender o que realmente significa ser diferente 
dentro deste aspecto das diversidades, porque há esta diferença ou até mesmo entender porque há tanto preconceito.

Ainda hoje se educa dentro de um padrão social, onde a fome e a pobreza fazem parte da nossa realidade.Vemos pessoas sendo discriminadas por sua classe ou sua cor. Isso faz parte de uma sociedade baseada em fatores de produtividade, a sociedade capitalista, que com sua política excludente, coloca o indivíduo num papel de marionete dentro do processo, em que valores como autonomia, solidariedade, cooperação estão sendo esquecidos em nome de uma política que exclui e muitas vezes desumanizar o próprio sujeito.

Diante desta consideração, a pluralidade cultural deve ser interpretada como uma possibilidade que permita ao educando a compreensão a cultura, o sistema social e político em que estamos envolvidos e que nossa sociedade é constituída por múltiplas diferenças que vive em constante conflito.

A pluralidade existente refere-se também às diferenças de gênero, etnias, desigualdade econômica, social e cultural em que o aluno está inserido, proporcionando o entendimento mais amplo da questão, e não apenas uma visão conteudista, sendo imposta pelos currículos escolares.

Os alunos observam o seu mundo e se comportam dentro dele da mesma maneira que são influenciados, de acordo comcostumes e atitudes de determinado grupo social.Com isso, pode ser considerado um agente transformador, a partir do momento em que ele aprende. Desse modo, os professores e pais são responsáveis pelos valores que são transmitidos assim como responsáveis pela construção da identidade da criança enquanto ser social.

Direcionar o processo de ensino-aprendizagem para as questões sociais é uma forma de transformar as crianças em cidadãos conscientes e críticos,capazes de identificar situações de discriminação socioeconômica, étnica e cultural. Estamos diante de sérios problemas de desigualdade social, pessoas sendo vítimas de preconceito, e é função do educador apresentar esses problemas mostrando formas em que o educando sinta-se capaz de conviver e agir corretamente diante de situações acima citadas.

Conceitos sobre o tema em questão devem ser apresentados durante a formação do ser cidadão de acordo com a realidade em que está inserido para que o mesmo esteja ciente de que o mundo em que vivemos é formado por indivíduos de diferentes etnias, religiões, opções sexuais, e que isso não influencia no caráter de uma pessoa, e sim as suas atitudes perante a realidade.

O trabalho no âmbito escolar com o tema Pluralidade Cultural é amplo e provoca transformações necessárias para uma boa convivência social entre os sujeitos, contemplando a construção de uma sociedade mais digna de se viver e adquirindo conhecimentos que tragam a compreensão das diferentes culturas que formam o Brasil.

\section{RELATO DA EXPERIÊNCIA}

\section{A pluralidade cultural como prática de uma escola}

Esta pesquisa realizou-se em uma escola na rede estadual de ensino do município de São Gabriel, com o objetivo de analisar o desenvolvimento de vários projetos pedagógicos, enfatizando assuntos que envolvam o tema transversal, a Pluralidade Cultural.

A realização e desenvolvimento desses projetos tinham como objetivo primordial conscientizar a comunidade escolar da importância de valorizar as diversidades étnicas e culturais 
da população. Percebeu-se, através do relato da Coordenadora, grande empenho da equipe diretiva e professores de desenvolver tais ensinamentos a fim de tornar o tema um processo de entendimento e respeito natural, com a finalidade de propiciar um ambiente escolar mais agradável para o processo ensino-aprendizagem globalizado, abrangendo as diversidades.

Através dos levantamentos e pesquisas realizados foi possível constatar que o alunado era bastante heterogêneo. Devido à presença de educandos de diferentes etnias, culturas, crenças e classe social fizeram-se necessários a construção e desenvolvimento de projetos, socializando os mesmos com o intuito de aceitar e respeitar as diversidades como um todo.

Ao iniciar o ano letivo de 2011 deste educandário, foi realizado o Projeto "Carnaval na Escola" o que possibilitou um resgate histórico e cultural sobre os diferentes povos, costumes, danças e músicas. O carnaval, a festa mais popular do país, com suas músicas e danças que variam de região para região, configuram fortes exemplos da importância das diferentes culturas existentes no nosso país, resgatando-a no âmbito escolar. A proposta teve êxito, pois possibilitou uma integração entre os diferentes alunos no início das atividades escolares. Através do relato da coordenadora responsável percebeu-se que houve uma maior aceitação das diferenças (sociais, econômicas) pelas crianças, pois todos interagiam em grupo em prol de um mesmo objetivo, vivenciando e experimentando as culturas de vários grupos.

Ainda no primeiro semestre, foi realizada uma gincana cultural envolvendo toda comunidade escolar com o objetivo de aproximartodos, valorizando o aprender brincando, valorizando diferentes costumes, opiniões e valores. Este trabalho envolvia a formação de grupos e a escolha das equipes. Houve uma aproximação entre os alunos, através de uma dinâmica utilizada com este propósito. No decorrer da gincana, que foi organizada de maneira interdisciplinar, foram avaliados diversos quesitos como: habilidade, coordenação motora, conhecimentos gerais/ atuais e conhecimentos específicos. Privilegiou-se a construção em conjunto das atividades para que houvesse, assim, o entrosamento e a união necessária para o sucesso de cada equipe. No relato com professores, percebeu-se que o verdadeiro objetivo desta atividade era a construção conjunta de valores a serem seguidos no decorrer do ano letivo. Foram trabalhados naturalmente os temas transversais, valorizando a ética e a construção de valores através de atividades interacionistas.

Constatou-se que a dinâmica "Prática através de filmes", também possibilitou maior entrosamento entre todos e maior aceitaçãoda diversidade, aprendeu-se através da observação, valorizar as diferenças. A festa de Hallowen proporcionou uma grande diversão em grupo e o entendimento/ aprendizado de diferentes culturas, crenças e tradições.

$\mathrm{O}$ projeto em que mais se percebeu comprometimento direcionado à Pluralidade Cultural foi a Programação "Projeto Consciência Negra", que envolveu a grande maioria da comunidade escolar cujo objetivo era divulgar a cultura negra a fim de valorizar os seus costumes, tradições, pratos típicos, danças, entre outros. A Escola contou com a participação do movimento afrodescendente do município para que o evento tivesse maior impacto e veracidade. Este projeto, além do aspecto interdisciplinar, objetivava possibilitar o entendimento da cultura deste povo, através de um resgate histórico. A grande maioria dos componentes curriculares desenvolveu atividades com o tema e assegurou o regaste histórico e a divulgação do entendimento desta importante etnia do nosso país. A parte artística do projeto desenvolveu-se através de construções teatrais realizadas a partir de textos construídos pelas turmas sobre o tema e através de letras musicais de capoeira. O grupo afrodescendente do nosso município 
proporcionou apresentações e oficinas típicas de danças, onde foram trabalhadas coreografias, movimento corporal, estudo de letras musicais e maior entendimento por toda comunidade escolar desta importante cultura.

Grande parte da Escola mobilizou-se na participação deste projeto, desde os alunos do Currículo, Ensino Fundamental ao Ensino Médio e percebeu-se um grande agregamento de ensinamentos e valores no findar de mais esse Projeto.

Houve algumas resistências por parte dos discentes e docentes na construção e realização dos projetos. Alguns grupos de professores mostraram-se apáticos e desmotivados na elaboração dessas atividades.Percebeu-se comodidade e falta e planejamento interdisciplinar. Quanto ao tema transversal pesquisado, diagnosticou-se, mesmo que sutilmente, que alguns educadores não abordam em sala de aula tal tema, nem os demais temas transversais. As aulas de Ensino Religioso muitas vezes são monopolizadas pelos ensinamentos Católicos, prendendo-se ao tema da Campanha da Fraternidade vigente. Segundo relato da coordenadora há uma grande resistência de alguns poucos educadores com a adaptação das inovações e mudanças educacionais previstas em lei.

O respeito às diversidades e diferenças culturais entre os alunos foi constatado com maior naturalidade nas turmas de currículo.

Diagnosticou-se que quanto mais tarde tal tema for abordado no ambiente escolar, mais desafiador será o entendimento e a conscientização de que vivemos numa sociedade onde conhecer e respeitar as diversidades plurais deve ser um processo natural.

Constatou-se através do diálogo com a equipe diretiva uma grande motivação, respaldo e incentivo para a realização dos Projetos. Pela entrevista por mim realizada, percebeu-se o comprometimento dos diversos setores da escola, bem como a atuação efetiva da Comunidade Escolar.

\section{CONSIDERAÇÕES FINAIS}

A educação no nosso país tem conquistado grandes avanços na busca de ofertar maior qualidade noprocesso ensino-aprendizagem, a fim de proporcionar a garantia de uma educação transformadora. Certamente grandes mudanças e inovações ainda devem acorrer.Constata-se que muitos educadores procuram mobilizar-se na construção deste processo, que é lento, mas essencial para obtenção de garantias para uma sociedade mais justa.

Tal melhoria sóserá possível quando os principais agentes deste processo: professor-aluno, perceberem sua importância e assumirem plenamente seus papéis. O processo ensinoaprendizagem vai além de uma prática de conteúdos programáticos, os educadores devem contextualizar seus conteúdos e os relacionar com os temas transversais de forma que alunos sejam levados a perceber a importância de respeitar as individualidades e as diversidades como um todo.

De acordo com os PCNs, nossa sociedade é caracterizada por uma grande heterogeneidade, o que é uma marca de nosso país. Pensando nessa realidade é que os professores devem estar atentos à sua prática pedagógica, para que esta esteja de acordo com as necessidades da realidade onde a escola está inserida. 
Os Parâmetros Curriculares apresentam uma proposta flexível e transversal, que deve ser concretizada de acordo com as peculiaridades regionais e locais, subsidiando o processo ensinoaprendizagem de modo a auxiliar o educador na sua tarefa de assumir como importante profissional, o lugar que lhe cabe pela responsabilidade e importância no processo de formação do povo brasileiro.

Os temas transversais devem estar inclusos oportunamente no cotidiano escolar, como um processo natural que garanta o respeito às diversidades existentes no país, em todos os âmbitos raciais, sociais, regionais, religiosos - a fim de que a educação possa ser um meio eficiente de construção da cidadania.

A Pluralidade cultural, que trata dessas questões citadas acima, enfatiza as diversas heranças culturais que convivem na população brasileira, oferecendo informações que contribuam para a formação de novas mentalidades, voltadas para a superação de todas as formas de discriminação e exclusão. (PCN, 1997, p.15). Este importante tema deve ser inserido obrigatoriamente no cotidiano escolar.

Através da pesquisa realizada na Escola Dr. Fernando Abbottpercebeu-se que há na escola uma busca através da realização de projetos, em desenvolver propostas que envolva a diversidade cultural como forma de integração social. Nesta perspectiva, observou-se grande mobilização de toda a comunidade escolar com a elaboração, realização e participação destas atividades.

Constatou-se que a realização de propostas pedagógicasatravés de projetos éintimamenteligada aos temas transversais, não sócontemplando a lei estabelecida, mas abordando temas transversais no cotidiano escolar.

Os mesmos foram analisados e percebeu-se nitidamente a interdisciplinaridade e a coerência da realização dos objetivos propostos em cada projeto. Foram percebidas a construção conjunta e a veracidade da proposta de cada trabalho, atendendo as necessidades dos docentes, na busca por maior êxito escolar.

O projeto que abrangeu o tema pesquisado de forma mais satisfatória foi o "Projeto Consciência Negra", trabalhado de maneira interdisciplinar, envolvendo toda a comunidade escolar, objetivado na perspectiva do conhecimento, da valorização da diversidade cultural e do desafio de eliminar estereótipos a elas relacionados. Estepropiciou uma reflexão sobre as diversidades e possibilitou maior valorização da cidadania multicultural e participativana comunidade escolar.

Contudo, salienta-se que apesar da proposta da realização de projetos interdisciplinares na escola, ainda há certa resistência dos educadores em transformar ações interdisciplinares nas práticas diárias em sala de aula.

\section{REFERÊNCIAS BIBLIOGRÁFICAS}

APPLE, Michael W. Educação e poder. Tradução de Maria Cristina Monteiro. Porto Alegre: Artes Médicas, 1989.

ARAUJO, Márcia Baiersdorf. Experiência de leitura e escrita no computador: a recepção ao software Luz das Letras por adultos em processo de alfabetização. 2000.127 f. Dissertação (Mestrado em Educação) - Universidade Federal do Paraná, Curitiba, 2000. 
BRASIL. Parâmetros Curriculares Nacionais: Introdução aos Parâmetros Curriculares nacionais/Ministério de Educação. Secretaria da Educação Fundamental. -3. ed. Vol. 01 - Brasília: A Secretaria, 2001.

.Parâmetros Curriculares Nacionais: Educação Física. Ministério da Educação e do Desporto. Secretaria de Educação Fundamental. Brasília: MEC / SEF, 1997.

CANDAU, Vera Maria; LEITE, Miriam Soares. A didática na perspectiva múlti/intercultural em ação: construindo uma proposta. Caderno de Pesquisa.São Paulo, v. 37, n.132, p. 731-758, set/dez. 2007.

DELORS, J. Educação: um tesouro a descobrir. São Paulo, Cortez, 1998.

FERNANDES, Florestan. O desafio educacional.São Paulo, Cortez, 1989.

FREIRE, Paulo. Pedagogia da Autonomia: saberes necessários à prática educativa. 21.ed. São Paulo: Paz e Terra, 2006.

UNESP, 2000. Pedagogia da Indignação: cartas pedagógicas e outros escritos. São Paulo:

.À sombra desta mangueira. São Paulo: Olho D'água, 2003.

Pedagogia da Autonomia: Saberes necessários à prática Educativa. Rio de Janeiro, Paz e Terra. 1997.

.Por uma pedagogia da pergunta. Rio de Janeiro: Paz e Terra, 1985.

HARGREAVES, Andy; FULLAN, Michael. A escola como organização aprendente: buscando uma educação de qualidade. Porto Alegre: Artmed, 2000.

MARTINS, Maria Anita Vivian. O professor como agente político. 4.ed.São Paulo: Loyola, 1995. MCLAREN, Peter. Multiculturalismo crítico. São Paulo: Cortez, 2000.

NÓVOA, Antônio. Os professores na virada do milênio: do excesso dos discursos à pobreza das práticas. Educação e pesquisa. São Paulo, v. 25, n. I, p. 11-20, jan/jun. 1999.

ROCHA, J.M. Sustentabilidade em questão: Economia, sociedade e meio ambiente. Jundia-SP: Paco editorial, 2011.

SARTORI, Jerônimo; WESCHENFELDER, Lorita Maria (Org.). Práticas pedagógicas: vivências e reflexões.Passo Fundo: Ed. Universidade de Passo Fundo, 2007. 